\title{
The Journal of \\ Microstructures of Organometal Trihalide Perovskites for Solar Cells: Their Evolution from Solutions and Characterization
}

\author{
Yuanyuan Zhou, ${ }^{* \dagger}$ Onkar S. Game, ${ }^{\dagger}$ Shuping Pang, ${ }^{\ddagger}$ and Nitin P. Padture* ${ }^{\dagger}$ \\ ${ }^{\dagger}$ School of Engineering, Brown University, 184 Hope Street, Providence, Rhode Island 02912, United States \\ ${ }^{\ddagger}$ Qingdao Institute of Bioenergy and Bioprocess Technology, Chinese Academy of Sciences, 189 Songling Road, \\ Qingdao 266101, P. R. China
}

\begin{abstract}
The use of organometal trihalide perovskites (OTPs) in perovskite solar cells (PSCs) is revolutionizing the field of photovoltaics, which is being led by advances in solution processing of OTP thin films. First, we look at fundamental phenomena pertaining to nucleation/growth, coarsening, and microstructural evolution involved in the solution-processing of OTP thin films for PSCs from a materials-science perspective. Established scientific principles that govern some of these phenomena are invoked in the context of specific literature examples of solution-processed OTP thin films. Second, the nature and the unique characteristics of OTP thin-film microstructures themselves are discussed from a materials-science perspective. Finally, we discuss the challenges and opportunities in the characterization of OTP thin films for not only gaining a deep understanding of defects and microstructures but also elucidating classical and nonclassical phenomena pertaining to nucleation/growth, coarsening, and microstructural evolution in these films. The overall goal is to have deterministic control over the solution-processing of tailored OTP thin films with desired morphologies and microstructures.
\end{abstract}

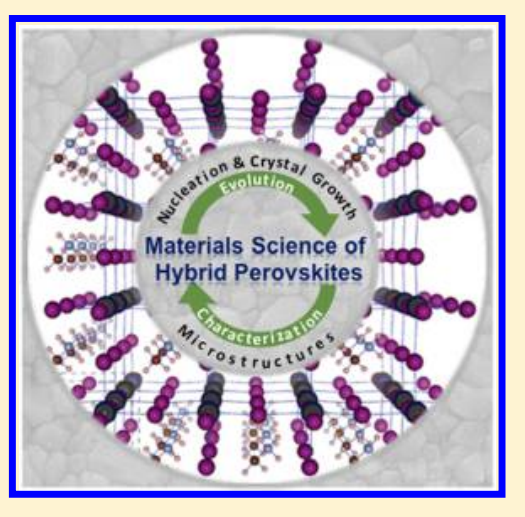

$\mathrm{T}$ he synthesis of organometal trihalide perovskites (OTPs) in 1978, where the " $\mathrm{A}$ " site in the $\mathrm{ABX}_{3}$ perovskite structure is occupied by an organic-molecule cation, ${ }^{1,2}$ represents a major milestone in the discovery of organic-inorganic hybrid materials. Although the structural understanding, solutionprocessing, and properties of this remarkable family of materials were further developed in the $1990 \mathrm{~s},{ }^{3}$ they did not find widespread interest until the first reported use of an OTPmethylammonium lead triiodide $\left(\mathrm{CH}_{3} \mathrm{NH}_{3} \mathrm{PbI}_{3}\right.$ or $\left.\mathrm{MAPbI}_{3}\right)-$ in solar cells in 2009, ${ }^{4}$ and a flurry of research activity ensued. ${ }^{5-8}$ The past four years have seen enormous amount of research devoted to OTPs and perovskite solar cells (PSCs) worldwide, ${ }^{9-12}$ and now, the certified record for power conversion efficiency (PCE) of PSCs stands at 20.1\%. ${ }^{13,14}$ The promise of low-cost solution-processed, high-efficiency PSCs, and its potential impact on the global renewable energy landscape, is driving this effort worldwide.

Significant research effort is being devoted to the processing of OTP thin films with the goal of optimizing their morphology (uniformity, coverage, roughness) and microstructure (grain size/distribution, texture) and of eliminating defects (voids, pinholes, grain boundaries), which influence the PSCs performance directly. ${ }^{12,15-17}$ Although some of the processing approaches have been highly successful, much of the effort remains somewhat heuristic. This is understandable considering the chemical/structural complexities, the vast parameter space, and the myriad chemicals/materials involved in the solution-processing of OTP thin films. Also, there is a paucity of detailed studies of the microstructures of the ubiquitously polycrystalline OTP thin films that are produced. This is surprising considering the important role microstructures play in determining the properties of OTP thin films and the behavior/performance of the resulting PSCs. The basic understanding of the evolution of OTP thin-film morphologies/ microstructures and the nature of the microstructures themselves is key to PSCs reaching their full potential, yet it remains largely obscure.

\section{The basic understanding of the evolution of OTP thin-film morphologies/microstructures and the nature of the micro- structures themselves is key to PSCs reaching their full potential, yet it remains largely obscure.}

This materials-science Perspective is divided into two parts. The first part addresses basic issues pertaining to nucleation/ growth, coarsening, and microstructural evolution-the key phenomena involved in the solution-processing of OTPs for PSCs. Wherever possible, established scientific principles that govern these phenomena are invoked in the context of specific literature examples of solution-processed OTP thin films, with the overall goal of providing guidelines for tailoring OTP thin films with desired morphologies and microstructures.

Received: August 23, 2015

Accepted: November 12, 2015

Published: November 12, 2015 
The second part addresses the nature of the OTP thin-film microstructures and the challenges and opportunities in their characterization.

Based on the architecture of the OTP layer, PSC embodiments are broadly classified as mesoscopic (OTP within mesoporous oxide scaffolds) and planar (flat OTP film) and more recently as mesoscopic-planar hybrid with a thin mesoscopic layer underneath a thick planar "capping" layer. ${ }^{15}$ Much of the discussion in this Perspective pertains to the planar part of the film. Because OTPs are inorganic-organic hybrid materials, they are solution-synthesized from either a precursor that has two components (organic and inorganic) or two separate precursors. Thus, the solution-processing of OTP thin films is broadly classified into two types of methods, ${ }^{12,15,16,18}$ "one-step" and "two-step", and they form the basis of the structure of this Perspective. "One-step" methods are the simplest and potentially least expensive, and they involve the direct growth of solid-state OTP thin films from a precursor mixture solution induced by supersaturation, whereas in the "two-step" methods, deliberate reaction between a predeposited precursor (typically solid) and a second precursor (solution, solid, or vapor) occurs, ultimately resulting in the formation of solidstate, polycrystalline OTP thin films.

"One-Step" Methods: Nucleation/Growth. Classical theories and analyses of nucleation pertaining to solution-synthesis of nanoparticles can be invoked in the context of solutiondeposition of OTP films. Consider a precursor-solution film deposited onto a substrate, where removal of the solvent will cause supersaturation in the film. There are several methods, or a combination of methods, in which the solvent can be removed. The simplest and the most widely used method is isothermal heating to cause solvent evaporation. ${ }^{12,15,16,18}$ Another supersaturation method is the addition of an antisolvent which extracts the precursor solvent, and it can simultaneously reduce the solubility of the precursor solute. ${ }^{19-22} \mathrm{~A}$ more recent method is the degassing of a liquid precursor. ${ }^{23}$ Assuming that the supersaturation of the precursor results in the appearance of OTP species (commonly referred to as "monomers", which can be atoms, ion, molecules, or formula units ${ }^{24}$ ), they can cluster together into single-crystal nuclei. These nuclei are likely to appear not only at the substrate/solution and colloidal particles/ solution interfaces but also within the precursor solution (Figure 1A). The former and the latter are referred to as heterogeneous and homogeneous nucleation, respectively. In the case of classical homogeneous nucleation, the total free-energy change $\Delta G$ as a function of nucleus radius, $r$, is given by ${ }^{25}$

$$
\Delta G(r)=\left(-\frac{4 \pi r^{3}}{3 V_{\mathrm{M}}}\right) R T \ln (S)+4 \pi r^{2} \gamma_{\mathrm{CL}}
$$

where $V_{M}$ is the molar volume of the nucleus, $R$ is the gas constant, $T$ is absolute temperature, $\gamma_{\mathrm{CL}}$ is the energy of liquid (L) - crystalline (C) nucleus interface, and $S$ is the supersaturation ratio defined as $S=C / C_{S}$, with $C$ as the solute concentration and $C_{S}$ as the solubility limit $\left(C>C_{S}\right)$. Figure $1 \mathrm{~B}$ plots eq 1 schematically, where $\Delta G$ goes through a maximum $\left(\Delta G^{*}{ }_{\text {Hom }}\right)$ at the critical nucleus radius $\left(r^{*}\right)$ indicating that nuclei with radii $r<r^{*}$ dissolve back into the precursor solution, whereas nuclei with radii $r>r^{*}$ are thermodynamically stable and they will grow. In the case of heterogeneous nucleation, where the nuclei form on foreign surfaces (e.g., substrate, colloidal particles), the energy barrier, $\Delta G^{*}{ }_{\mathrm{Het}}$ is reduced significantly through effective reduction of the interface energy,

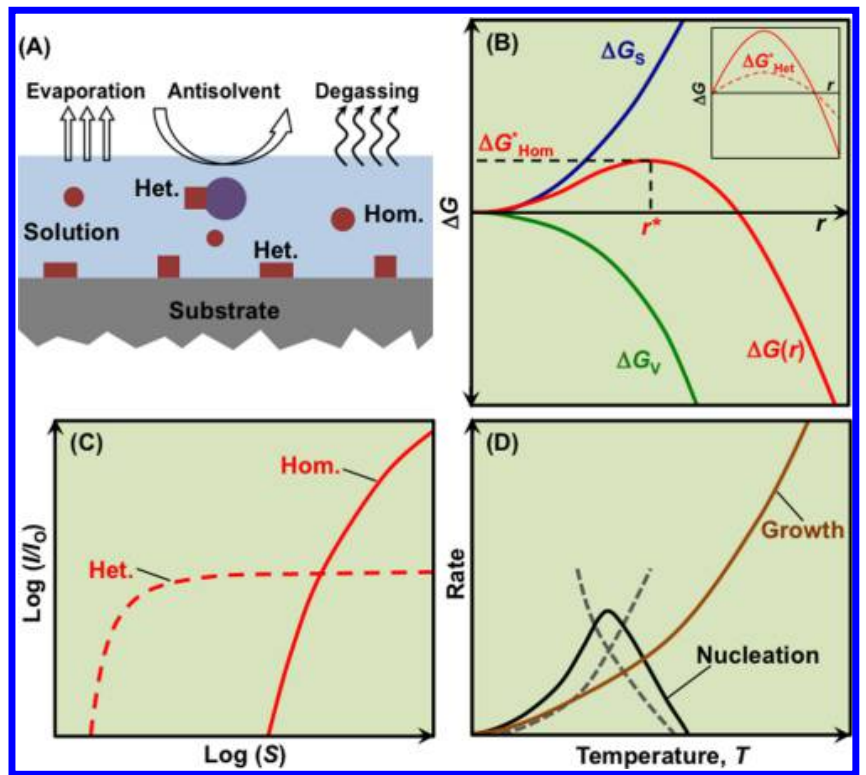

Figure 1. Schematic illustrations of classical: (A) homogeneous and heterogeneous nucleation during supersaturation of thin-film solution; (B) free energy change $(\Delta G)$, sum of surface $\left(\Delta G_{S}\right)$, and volume free energy changes $\left(\Delta G_{\mathrm{V}}\right)$, as a function of nucleus radius $(r)$ for homogeneous nucleation (inset: heterogeneous nucleation); (C) normalized nucleation rate as a function of supersaturation ratio $(S)$ for homogeneous and heterogeneous nucleation; and (D) nucleation and growth rates as a function of temperature.

$\gamma f(\theta)$, where $0<f(\theta)<1$ (Figure 1B inset). The parameter $f(\theta)$ is given $\mathrm{by}^{26}$

$$
f(\theta)=\frac{1}{4}\{2+\cos (\theta)\}\{1-\cos (\theta)\}^{2}
$$

where $\cos (\theta)=\left(\gamma_{\mathrm{SL}}-\gamma_{\mathrm{SC}}\right) / \gamma_{\mathrm{CL}}{ }^{27}$ with $\gamma_{\mathrm{SL}}$ and $\gamma_{\mathrm{SC}}$ being the energies of the substrate/liquid $(\mathrm{S} / \mathrm{L})$ and the substrate/ crystalline nucleus $(\mathrm{S} / \mathrm{C})$ interfaces, respectively, and $\theta$ is the contact angle. However, unlike homogeneous nucleation, heterogeneous nucleation sites are limited by the available areas of the substrate and the colloidal particles within the precursor solution.

In classical nucleation theory, the rate of nucleation is given by $^{25,26}$

$$
I \propto \exp \left(\frac{-Q_{\mathrm{D}}}{R T}\right) \exp \left(\frac{-\Delta G^{*}}{R T}\right)
$$

where $I=I_{\mathrm{Hom}}$ for $\Delta G^{*}=\Delta G^{*}{ }_{\mathrm{Hom}}(f(\theta)=1)$ and $I=I_{\mathrm{Het}}$ for $\Delta G^{*}=\Delta G^{*}{ }_{\text {Het }}(0<f(\theta)<1), Q_{D}$ is the activation energy for the transport of "monomers" to the nucleus/solution interface. Equation 3 is plotted schematically in Figure 1C (at constant T) showing the ease of heterogeneous nucleation at low $S$, and the importance of homogeneous nucleation at high $S .{ }^{28}$ For the growth of uniform films, it is necessary to form heterogeneous nuclei of high density on the substrate rather than heterogeneous nucleation on colloidal particles and homogeneous nucleation. With regards to temperature dependence (at constant $S$ ), the first exponential term in eq 3 increases with increasing temperature, whereas the second exponential term decreases, and they are illustrated schematically as left and right dashed curves in Figure 1D, respectively. The net result is that the overall nucleation rate goes through a maximum as a function of temperature.

In the case of solution-processed OTP thin films, the situation is more complicated because the supersaturation process may 
not simply lead to the formation of phase-pure OTP singlecrystal nuclei. ${ }^{19,29,30}$ For example, consider the simplest case of supersaturation by evaporation during spin-coating and subsequent heating of a precursor-solution thin film of stoichiometric MAI: $\mathrm{PbI}_{2}$ in 1:1 molar ratio in a polar solvent to result in $\mathrm{MAPbI}_{3}$ - the most widely studied OTP for PSCs. Generally, polar solvents such as dimethyformamide (DMF), dimethyl sulfoxide (DMSO), and N-methyl-2-pyrrolidone (NMP) dissolve the inorganic $\mathrm{PbI}_{2}$ salt, where a strong coordination bond forms between the $\mathrm{O}$-donor ligands in the solvent and the $\mathrm{Pb}$ atoms. ${ }^{31}$ The organic halide precursor (MAI) dissolves more readily in the solvent, and it can coordinate to the $\mathrm{Pb}$ atoms. The $\gamma$-butylrolacetone (GBL) solvent is different because it dissolves $\mathrm{PbI}_{2}$ only in the presence of MAI in the solution. These precursor solutions are not considered to be "true" solutions as they can contain colloidal particles. ${ }^{32}$ Although the exact composition and nature of the colloidal particles are not known, they are generally complex adducts of the type MAI. $\mathrm{PbI}_{2} \cdot x \mathrm{DMF}^{29}$ or $\mathrm{MAI} \cdot \mathrm{PbI}_{2} \cdot x \mathrm{DMSO} .^{19,33,34}$ These colloidal particles can serve as heterogeneous nucleation sites, and they can assemble into bulk structures within the solution because of the strong van der Waals bonding. Thus, the overall $\mathrm{MAPbI}_{3}$ nuclei density on the substrate is likely to be low, resulting in the subsequent exaggerated growth of the few nuclei and incomplete coverage during heat-treatment. Figure $2 \mathrm{~A}$ is a typical

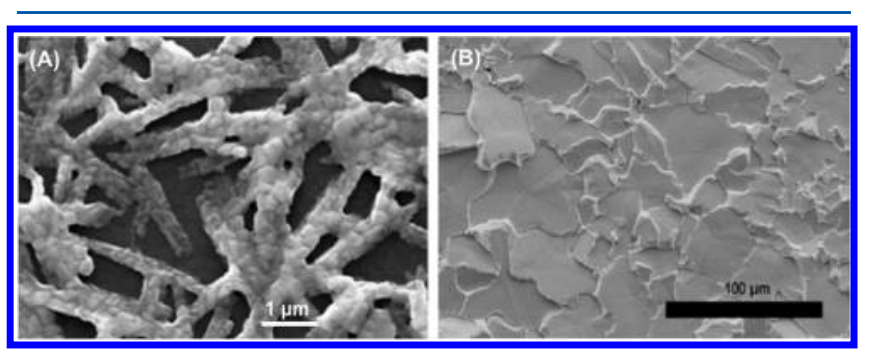

Figure 2. Top-view SEM micrographs of "one-step" solutionprocessed $\mathrm{MAPbI}_{3}$ perovskite thin films using different solvents: (A) $\mathrm{DMF}^{35}$ and (B) MAF ionic liquid. ${ }^{39}$ Reprinted with permission of Royal Society of Chemistry (copyright 2015) and American Chemical Society (copyright 2015).

example of such a $\mathrm{MAPbI}_{3}$ thin film, showing polycrystalline acicular $\mathrm{MAPbI}_{3}$ perovskite and regions of bare substrate. ${ }^{35}$ To improve coverage, approaches such as controlling the solvent evaporation rate, ${ }^{36}$ adjusting the solvent properties (e.g., volatility, boiling point, coordination power), ${ }^{37}$ and improving wetting with substrate (e.g., interfacial-layer insertion ${ }^{38}$ ) has met with some success through the manipulation of the nucleation parameters in eq $3(T, S, \gamma, f(\theta))$. However, because of the complexity of these organic-solvent systems, the basic understanding of the relationship between the solvent properties and the nucleation behavior remains obscure. In this context, Moore et al. ${ }^{39}$ used an ionic liquid (methylammonium formate or MAF) to form a solution of perovskite precursors, where only phasepure $\mathrm{MAPbI}_{3}$ crystallizes upon heating, representing a more ideal case of nucleation described earlier. The resulting dense $\mathrm{MAPbI}_{3}$ perovskite thin films have full-coverage (Figure 2B), ${ }^{39}$ most likely due to a high density of heterogeneous $\mathrm{MAPbI}_{3}$ nuclei.

It has been shown that the use of additives can also suppress this exaggerated growth and result in better-coverage $\mathrm{MAPbI}_{3}$ perovskite thin films. The additives are incorporated in the precursor solution either by simply adding the excess chemicals (e.g., MAI, ${ }^{40} \mathrm{MACl}^{41} \mathrm{NH}_{4} \mathrm{Cl}^{42}$ ) or by using alternative lead sources (e.g., $\mathrm{PbCl}_{2}{ }^{7,43} \mathrm{~Pb}\left(\mathrm{C}_{2} \mathrm{H}_{3} \mathrm{O}_{2}\right)_{2}$ (or $\mathrm{PbAc}_{2}$ ), ${ }^{43,44}$ $\left.\mathrm{Pb}\left(\mathrm{NO}_{3}\right)_{2}{ }^{43}\right)$ instead of $\mathrm{PbI}_{2}$. In this context, Zhang et al. ${ }^{44}$ in a comprehensive, comparative study have obtained dense $\mathrm{MAPbI}_{3}$ thin films with full-coverage by using $\mathrm{PbAc}_{2}$ as the $\mathrm{Pb}$ source $\left(\mathrm{PbAc}_{2}: \mathrm{MAI}:: 1: 3\right)$, whereas the use of $\mathrm{PbI}_{2}$ $\left(\mathrm{PbI}_{2}: \mathrm{MAI}:: 1: 3\right)$ or $\mathrm{PbCl}_{2}\left(\mathrm{PbCl}_{2}: \mathrm{MAI}:: 1: 3\right)$ as $\mathrm{Pb}$ sources results in porous thin films with poorer coverage. On the basis of some ex situ characterization studies, they suggest that this could be due to the much higher nucleation rate and nuclei density on the substrate in the $\mathrm{PbAc}_{2}$ case, ${ }^{44}$ which may be aided by the more facile removal of the excess organic salt from the precursor. ${ }^{43,44}$ In the case of formamidinium lead triiodide $\left(\mathrm{HC}\left(\mathrm{NH}_{2}\right)_{2} \mathrm{PbI}_{3}\right.$ or $\left.\mathrm{FAPbI}_{3}\right) \mathrm{OTP}$, which is also gaining interest for use in PSCs, ${ }^{13}$ the additive-assisted one-step route (e.g., the use of $\mathrm{PbCl}_{2}{ }^{45}$ precursor, the addition of $\mathrm{HI}{ }^{46}$ or the use of $\mathrm{HPbI}_{3}{ }^{47}$ precursor) has been shown to result in bettercoverage $\mathrm{FAPbI}_{3}$ thin films.

As will be discussed later, there is thermodynamic driving force and sufficient thermally activated transport for stable nuclei to grow during supersaturation, which can occur simultaneously as new nuclei are being formed. Since the growing nuclei compete for the available "monomers" with the new nuclei that are being formed, the overall nucleation rate is expected to decrease at elevated temperature (Figure 1D), which can result in a wider grain-size distribution and nonuniformity in the film. In this context, instead of heating, room-temperature antisolvent-solvent extraction is another way to achieve supersaturation, boosting the nucleation rate while suppressing the rate of thermally-activated growth, because the latter increases exponentially with temperature (Figure 1D). ${ }^{21}$ In this process, an antisolvent, which is typically nonpolar (e.g., diethyl ether) and has high miscibility for high-boiling-point polar precursor-solvents (e.g., GBL, NMP), is used to extract the precursor-solvent in an antisolvent bath (Figure $3 \mathrm{~A}) .^{21}$ Also, the addition of antisolvent can reduce the solubility of the solute in the precursor solvent by influencing the polarity in a "salting out" process. ${ }^{48}$ Even at room temperature, antisolvent-solvent extraction is a very rapid process (seconds to minutes) for the removal of precursor solvent, compared to heating, which further suppresses growth. The net result is an ultrasmooth, fine-grained perovskite $\left(\mathrm{MAPbI}_{3}\right)$ thin film with full coverage (Figure $3 \mathrm{~B}){ }^{21}$ Dripping of the antisolvent (e.g., chlorobenzene) onto precursor films followed by heating also results in dense, full-coverage $\mathrm{MAPbI}_{3}$ thin films (Figure 3C). ${ }^{20}$ In a related "solvent-engineering" approach published simultaneously, toluene antisolvent was dripped onto $\mathrm{MAPbI}_{3}$ precursor solution film during spin-coating. ${ }^{19}$ However, in that case, the toluene-dripping step promotes the formation of an intermediate $\mathrm{MAI} \cdot \mathrm{PbI}_{2} \cdot \mathrm{DMSO}$ complex rather than $\mathrm{MAPbI}_{3}$, which upon heating transforms to full-coverage, dense $\mathrm{MAPbI}_{3}$ thin films (Figure 3D). ${ }^{19}$ Most recently, it was shown that solid $\mathrm{MAPbI}_{3}$ perovskite when exposed to methylammonium gas $\left(\mathrm{CH}_{3} \mathrm{NH}_{2}\right)$ at room temperature turns into a clear liquid solution $\left(\mathrm{MAPbI}_{3} \cdot x \mathrm{CH}_{3} \mathrm{NH}_{2}\right)$ that spreads, which can now serve as a precursor. ${ }^{23}$ Here, supersaturation occurs as a result of degassing (by lowering the $\mathrm{CH}_{3} \mathrm{NH}_{2}$ partial pressure) at room temperature, which leads to very rapid (seconds) nucleation of $\mathrm{MAPbI}_{3}$ grains (Figure 3G). ${ }^{23}$ This has been shown to heal defects in poor-coverage thin films, resulting in full-coverage, fine-grained $\mathrm{MAPbI}_{3}$ thin films with significantly improved crystallinity and texture (Figure $3 \mathrm{E}$ and F). ${ }^{23}$ Thus, the two room-temperature "one-step" methods highlighted here (Figure $3 \mathrm{~A}-\mathrm{C}$ and $\mathrm{E}-\mathrm{G}$ ) appear to be nucleation-dominated, but the exact nucleation mechanisms are not known, and they 


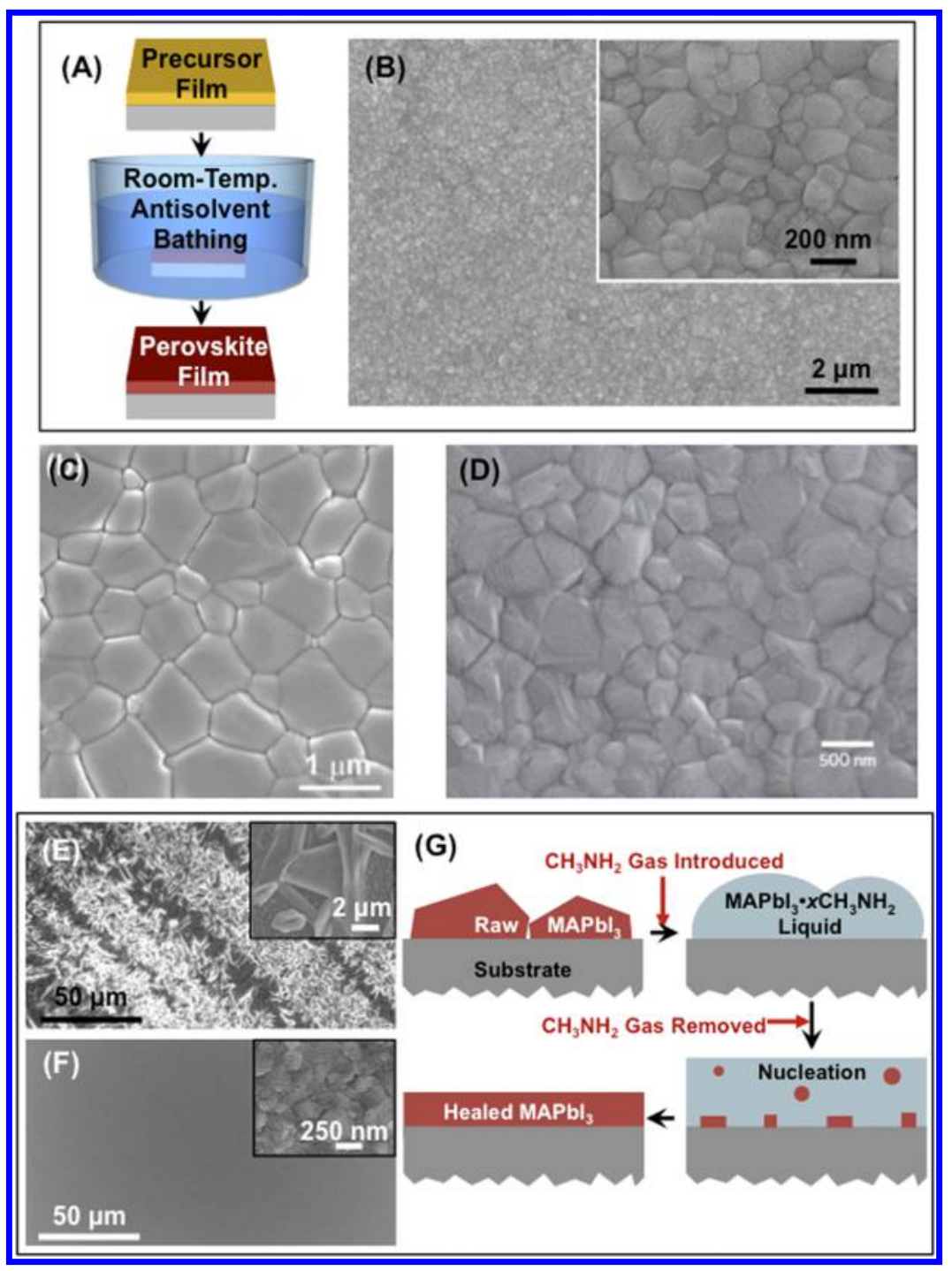

Figure 3. (A) Schematic illustration of the "antisolvent-solvent extraction" process for the "one-step" deposition of $\mathrm{MAPbI}_{3}$ perovskite thin films and (B) top-view SEM micrograph of the resulting $\mathrm{MAPbI}_{3}$ perovskite thin film. ${ }^{21}$ Top-view SEM micrographs of $\mathrm{MAPbI}_{3}$ perovskite thin films deposited by (C) the "fast-deposition-crystallization" method ${ }^{20}$ and (D) "solvent-engineering" approach. ${ }^{19}$ Top-view SEM micrographs of MAPbI ${ }_{3}$ perovskite: (E) raw film; (F) methylamine-gas-induced healed film; (G) schematic illustration of the healing process. ${ }^{23}$ Reprinted with permission of Royal Society of Chemistry (copyright 2015), Wiley (copyright 2014, 2015), and Nature Publishing Group (copyright 2014).

present unique opportunities for fundamental studies, with farreaching implications for the high-throughput processing of large-area, high-quality perovskite thin films for high-PCE PSCs.

Once stable heterogeneous crystalline nuclei are formed, they will grow to reduce the overall free energy of the system, provided $C>C_{s}$. All indications are that the growth of OTP thin films occurs by a process akin to nonepitaxial VolmerWeber mechanism. ${ }^{49}$ In this process, the 3-D nuclei (or "islands") grow both vertically and laterally, ultimately coalescing into a dense polycrystalline thin film. $^{50}$ [The other two types of major mechanisms, Frank-van der Merwe and Stranski-Krastanov, involve monolayer full coverage of the substrate, which is typically relevant in the case of epitaxial thin-films growth. ${ }^{50}$ ] The rate-limiting step in this classical growth process can be $\mathrm{b}^{50}$ (i) diffusion of "monomers" toward the nucleus or (ii) attachment of the "monomers" to the surface of the crystalline nucleus by interface reaction. For solution processing of OTP thin films at 25 to $150{ }^{\circ} \mathrm{C}$, the growth may not be limited by diffusion; instead, it is most likely controlled by interfacereaction kinetics.

\section{Because the fate of the final microstructure of these OTP thin films, and ultimately the PSC performance, depends on initial nucleation/growth, it is important to be able to rationally design and deterministically control the nucleation/growth process.}

Thus, having a high density of starting nuclei on the substrate is likely to result in uniform, full-coverage "one-step" solutionprocessed OTP thin films after coalescence, compared to having few nuclei. Because the fate of the final microstructure of these OTP thin films, and ultimately the PSC performance, depends on initial nucleation/growth, it is important to be able to rationally design and deterministically control the nucleation/growth process. This has the potential of having a 
lasting impact because the inherent simplicity and economy of the "one-step" methods are attractive attributes for the commercial manufacturing of PSCs. Thus, a basic understanding of this process in OTPs is absolutely necessary for making transformative progress in this area. In this context, although classical nucleation/growth by "monomers" attachment is discussed here as the foundational step, nonclassical nucleation/ growth by the addition and attachment ("oriented" in some case) of particles that range from multi-ion complexes to fully formed nanoparticles will need to be considered (Figure 4). ${ }^{24}$

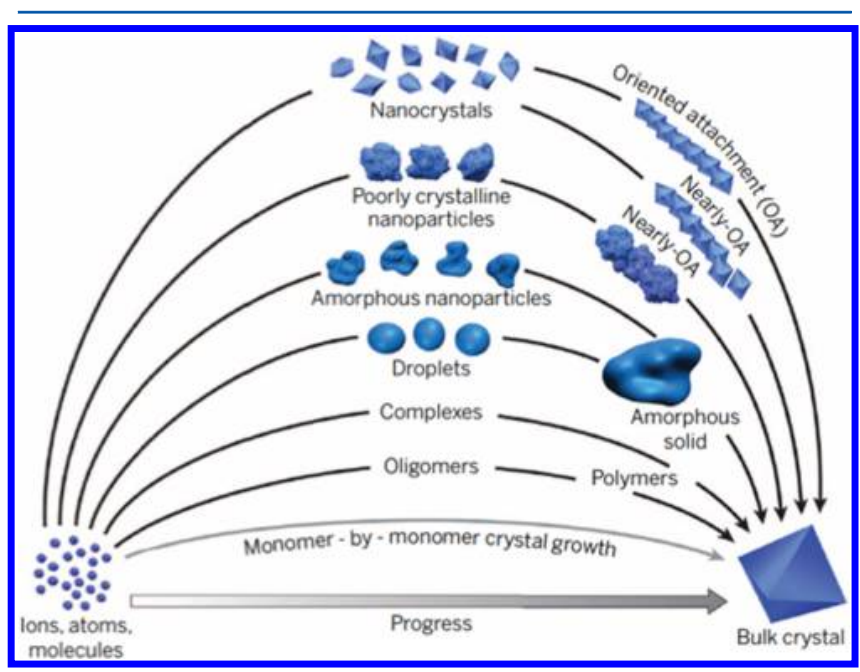

Figure 4. Pathways to nucleation/crystallization by classical "monomer" and nonclassical particle (multi-ion complexes to fully formed nanocrystals) attachment. ${ }^{24}$ Reprinted with permission of American Association for the Advancement of Science (copyright 2015).

Detailed in situ and ex situ characterization experiments are key to identifying the range of possible nonclassical nucleation/ growth pathways in OTPs.

\section{Detailed in situ and ex situ characterization experiments are key to identifying the range of possible non-classical nucleation/ growth pathways in OTPs.}

"Two-Step" Methods: Nucleation/Growth. Typically, "twostep" methods entail deliberate reaction between two precursors on a substrate to result in the formation of solidstate OTP thin films, where the precursors can be in solid, liquid, and vapor forms. (The discussion of all-vapor-based methods ${ }^{8}$ is omitted, as this Perspective mainly pertains to solution processing.) The "two-step" methods are typically more involved compared to the "one-step" methods, but they were introduced to gain better control over the formation of OTPs by moderating the rapid reaction between the organic and the inorganic parts of the precursor. ${ }^{51-53}$ The three representative "two-step" methods are (i) solid-liquid by Burschka et al., ${ }^{54}$ (ii) solid-solid by Xiao et al., ${ }^{55}$ and (iii) solid-vapor by Chen et al., ${ }^{56}$ with most of the other methods being some variation of these three. The simple reactions pertaining to these three methods, in the context of $\mathrm{MAPbI}_{3}$ perovskite thin film deposition, respectively, are

$$
\mathrm{PbI}_{2}(\mathrm{~s})+\mathrm{MAI}(\text { soln }) \rightarrow \mathrm{MAPbI}_{3}(\mathrm{~s})
$$

(Reaction 1)

$$
\begin{aligned}
& \mathrm{PbI}_{2}(\mathrm{~s})+\mathrm{MAI}(\mathrm{s}) \rightarrow \mathrm{MAPbI}_{3}(\mathrm{~s}) \\
& \mathrm{PbI}_{2}(\mathrm{~s})+\mathrm{MAI}(\mathrm{g}) \rightarrow \mathrm{MAPbI}_{3}(\mathrm{~s})
\end{aligned}
$$

(Reaction 2)

(Reaction 3)

In the first method, solid $\mathrm{PbI}_{2}$ thin film is first deposited onto a substrate, which is then dipped into a liquid solution of MAI. ${ }^{54}$ If the $\mathrm{PbI}_{2}$ layer is dense, Reaction 1 is likely to start immediately at the top of the $\mathrm{PbI}_{2}$ layer, resulting in the nucleation of $\mathrm{MAPbI}_{3}$ there. However, the nature of this nucleation process is not clear. This is further compounded by the fact that this reaction can take a long time, and that the as-formed $\mathrm{MAPbI}_{3}$ perovskite can dissolve back in the MAI solution, ${ }^{54,56}$ resulting in rough films (see, e.g., Figure $5 A^{56}$ ). In the second method, the MAI precursor solution is spin-coated onto the solid $\mathrm{PbI}_{2}$ layer and dried to result in a two-layer stack of solid $\mathrm{PbI}_{2}$ and MAI, which is then heat-treated (at $100{ }^{\circ} \mathrm{C}$ ) to carry out Reaction $2 .{ }^{55}$ It has been suggested that the MAI solution starts reacting with the $\mathrm{PbI}_{2}$ layer during spin-coating, and that during the interdiffusion heat treatment, the formation of solid, fine-grained $\mathrm{MAPbI}_{3}$ perovskite is complete within seconds (Figure 5B). ${ }^{55}$ Thus, the nature of nucleation of $\mathrm{MAPbI}_{3}$ crystals during this fast process, and how the two stacked layers of solid $\mathrm{PbI}_{2}$ and MAI convert to a single solid layer of $\mathrm{MAPbI}_{3}$, is also not clear. In the third method, MAI vapor is reacted with the previously deposited $\mathrm{PbI}_{2}$ layer at an elevated temperature (at $150{ }^{\circ} \mathrm{C}$ ), resulting in solid $\mathrm{MAPbI}_{3}$ perovskite. ${ }^{56}$ Here, results from interrupted experiments show evidence of what appear to be $\mathrm{MAPbI}_{3}$ nucleation-centers $(\sim 10 \mathrm{~nm})$ on the surface of the $\mathrm{PbI}_{2}$ layer initially, and the reaction is complete in $2 \mathrm{~h}$ (Figure 5C). ${ }^{56}$ Thus, the likely scenario for the evolution of polycrystalline OTP thin films in these three "two-step" processes is illustrated schematically in Figure 5D. Some type of nucleation process at the surface of the inorganic (e.g., $\mathrm{PbI}_{2}$ ) is inevitable as a precursor to the formation of a continuous OTP (e.g., $\mathrm{MAPbI}_{3}$ ) layer. Further reaction between the organic and the inorganic is then governed by solid-state diffusion of the various chemical species through the as-formed OTP layer, which is likely to control the growth of the polycrystalline OTP layer until all the solid inorganic has been consumed. There is extensive literature on the thermodynamics and kinetics of diffusioncontrolled reactions in materials science that can be invoked here. ${ }^{57}$ Consider the schematic illustration in Figure 5E depicting the formation of $\mathrm{ABX}_{3}$ perovskite from the reaction between the AX organic and the $\mathrm{BX}_{2}$ inorganic. The thickness $(y)$ of the as-formed $\mathrm{ABX}_{3}$ is given by

$$
y^{2}=K_{1} t
$$

where $K_{1}$ is a rate constant given by $K_{\mathrm{O} 1} \exp \left(-Q_{\mathrm{R}} / R T\right)$, with $Q_{R}$ being activation energy for the solid-state diffusion process controlling the reaction. There are three possible situations for solid-state diffusion through the as-formed, dense $\mathrm{ABX}_{3}$ controlling this reaction, viz, diffusion of both $\mathrm{A}^{+}$and $\mathrm{X}^{-}$ (Figure $5 \mathrm{~F}$ ), both $\mathrm{B}^{+}$and $2 \mathrm{X}^{-}$(Figure $5 \mathrm{G}$ ), or counterdiffusion of $2 \mathrm{~A}^{+}$and $\mathrm{B}^{+}$(Figure $\left.5 \mathrm{H}\right) .^{57}$ It is assumed that the slower of the two species in each situation will control the overall diffusion in order to avoid charge imbalance. At which interface and how quickly the new $\mathrm{ABX}_{3}$ forms will depend on the controlling diffusion process, which is not known at this time in any of the "two-step" processes.

The "two-step" reaction synthesis of OTPs is further complicated by volume expansion issues and the formation of intermediate complex adducts. Because the densities of $\mathrm{PbI}_{2}$, $\mathrm{MAI}$, and $\mathrm{MAPbI}_{3}$ perovskite are $6.26 \mathrm{~g} \cdot \mathrm{cm}^{-3}, 4.29 \mathrm{~g} \cdot \mathrm{cm}^{-3}$, and 


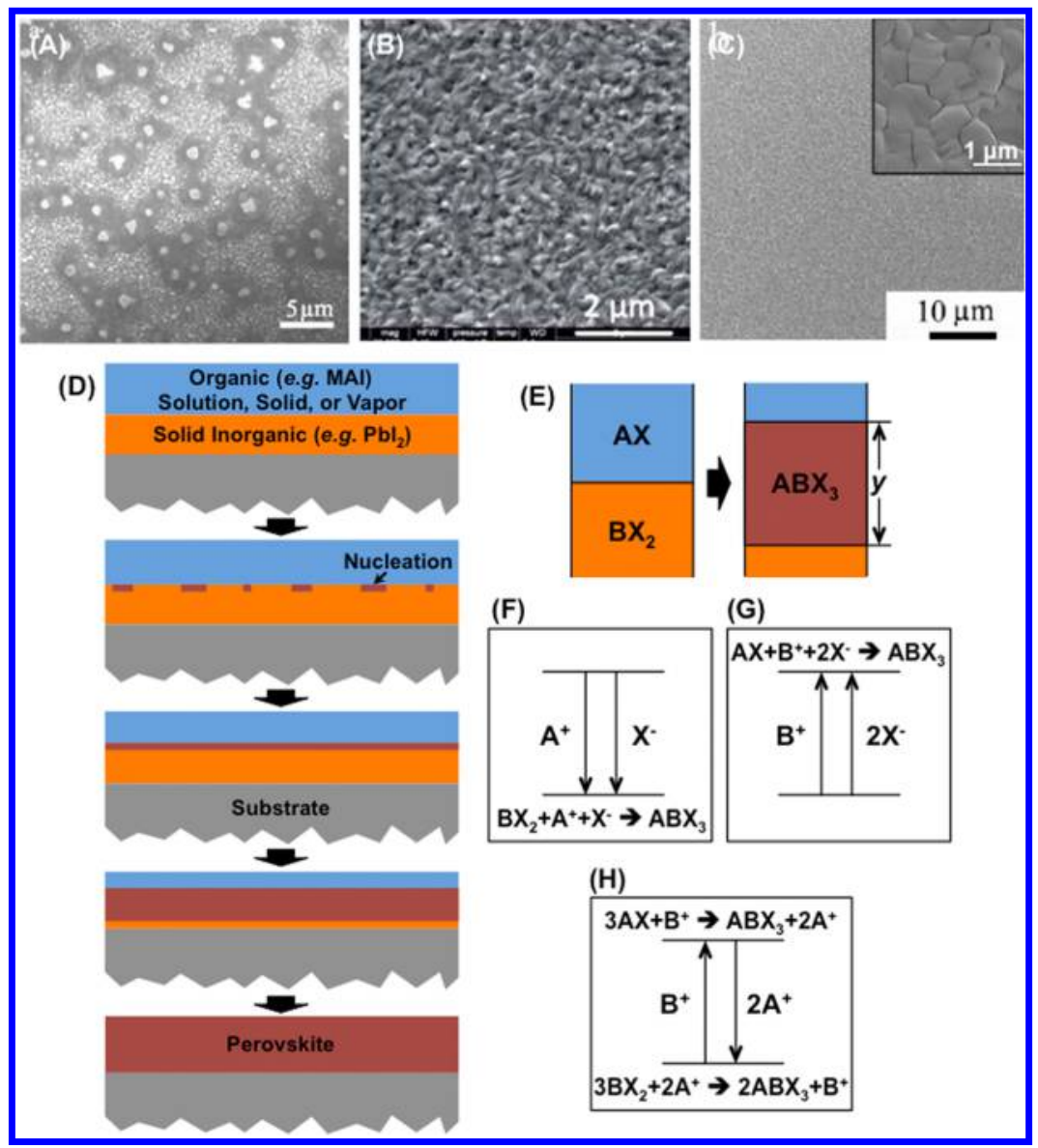

Figure 5. Top-view SEM micrographs pertaining to "two-step" deposited $\mathrm{MAPbI}_{3}$ perovskite thin films corresponding to (A) Reaction 1 method, ${ }^{56}$ (B) Reaction 2 method, ${ }^{55}$ and (C) Reaction 3 method. ${ }^{56}$ Schematic illustrations of: (D) possible stages in the "two-step" methods, (E) "two-step" reaction, and $(\mathrm{F})-(\mathrm{H})$ the possible reaction pathways. ${ }^{57}$ Reprinted with permission of American Chemical Society (copyright 2014) and Royal Society of Chemistry (copyright 2014).

$4.16 \mathrm{~g} \cdot \mathrm{cm}^{-3}$, respectively, ${ }^{58-60}$ the intercalation of MAI into predeposited $\mathrm{PbI}_{2}$ films will induce a large volume expansion, the effect of which needs to be considered. Schlipf et al. ${ }^{59}$ have probed, using grazing-angle X-ray scattering, the inner film morphology during the "two-step" evolution of OTPs for a dense predeposited $\mathrm{PbI}_{2}$ film (Reaction 1). They concluded that the lateral confinement by the substrate forces the OTP grains to grow in the vertical direction. The strain due to the lateral constraint can possibly lead to cracking, delamination, and high roughness, and also elevation of the energy barrier for perovskite formation. In this context, the use of a porous $\mathrm{PbI}_{2}$ film is suggested for the accommodation of the volume expansion. ${ }^{60}$ Also, additives (e.g., MAI) are incorporated into the predeposited dense $\mathrm{PbI}_{2}$ films ${ }^{61}$ or films of density-matched adduct complexes (e.g., $\mathrm{PbI}_{2} \cdot x \mathrm{DMSO}$ ) are used to alleviate the volume expansion issue. ${ }^{13,62}$ In the latter, the grain morphologies of the adduct complex films and the final $\mathrm{MAPbI}_{3}$ perovskite films are observed to be similar, ${ }^{62}$ suggesting shape-preserving conversion.

Thus, these effects, and other hitherto unknown effects, will need to be considered in studying the nucleation/growth process in "two-step" methods for a deeper understanding, and to evaluate how important nucleation is in determining the final OTP thin-film microstructures. Once again, detailed in situ and ex situ characterization studies are key. This understanding will enable rational design of existing, or altogether new, "two-step" methods in achieving better control over the processes and further improvements in the quality of OTP films produced.
Coarsening/Grain Growth. For solar cells based on polycrystalline semiconductors, it is generally desirable to have large grains because defects such as grain boundaries degrade the PV performance. ${ }^{63}$ In the case of OTPs, there is increasing evidence to suggest that charge recombination occurs at grain boundaries because of their high charge-trap densities, resulting in shorter carrier diffusion lengths and lifetimes, influencing PCE and hysteresis. ${ }^{17,64,65}$ Also, the grain size is likely to affect other properties such as conductivity, dielectric constant, carrier mobility, and so forth. Though it is understandable that any grain boundaries within the thickness of the OTP thin films (in-plane) could be detrimental, the direct benefit of having grain size much larger than the film thickness (through-thickness grain boundaries) has not been demonstrated unequivocally. Nevertheless, as the PCEs of PSCs approach the theoretical maximum, it will become necessary to reduce the defect density in OTPs, including the reduction, or elimination, of grain boundaries. ${ }^{17}$ Also, other OTP applications are starting to emerge, such as lasers, light-emitting diodes (LEDs), sensors, and so forth, where large-grained or single-crystal materials will be needed. ${ }^{17}$

The grains in a dense, polycrystalline OTP thin film will coarsen given sufficient thermal energy and time. The two most important and relevant classical coarsening mechanisms are solid-state grain growth and liquid-mediated Ostwald ripening. The thermodynamic driving force for both mechanisms is the differences in the curvatures. In the case of solid-state grain growth, it is convenient to invoke topological considerations; 


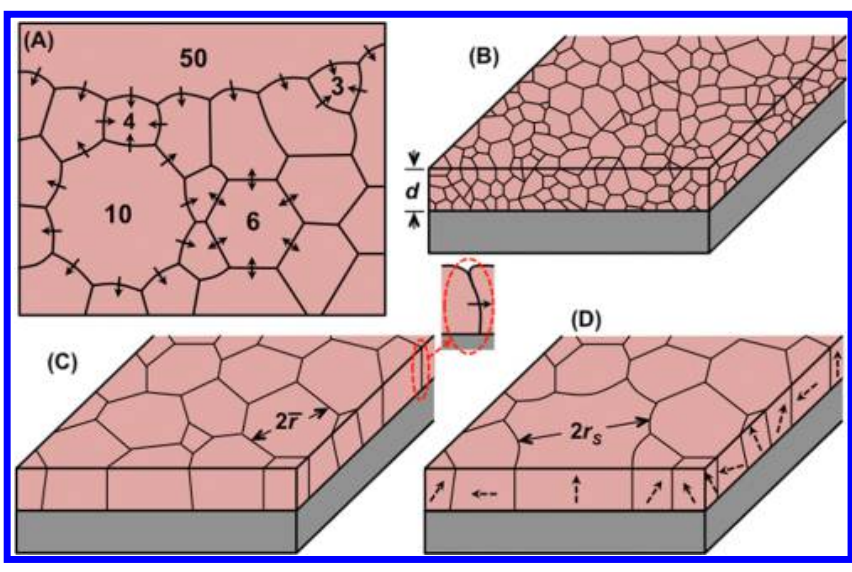

Figure 6. Schematic illustrations of (A) a 2-D microstructure showing motion of grain boundaries (number of sides to a grain is indicated), ${ }^{59}$ (B) fine-grained thin film (inset: grain-boundary groove), (C) coarsegrained "stagnated" thin film, and (D) secondary grain growth. ${ }^{66}$ Reprinted with permission of Wiley (copyright 1976) and Annual Reviews Inc. (copyright 1990).

Figure $6 \mathrm{~A}$ is a $2-\mathrm{D}$ schematic illustration of a polycrystalline material containing grains of different sizes and coordination numbers (sides). ${ }^{57}$ Here, grains with six sides (dihedral angle $\phi=120^{\circ}$ ) are stable, whereas grains with more than six sides will grow (concave grain boundaries, $\phi<120^{\circ}$ ) at the expense of neighboring grains with fewer than six sides, which will shrink (convex grain boundaries, $\phi>120^{\circ}$ ). Grain coarsening rate is then given by ${ }^{57}$

$$
r_{\mathrm{t}}^{n}-r_{\mathrm{o}}^{n}=K_{2} t
$$

where $r_{0}$ and $r_{\mathrm{t}}$ are grain radii at time zero and at $t$, respectively, exponent $n \sim 2$, and $K_{2}$ is the rate constant given by $K_{\mathrm{O} 2} \exp \left(-Q_{\mathrm{B}} / R T\right)$, with $Q_{\mathrm{B}}$ being the activation energy for grainboundary motion, which is related to the solid-state diffusion of the relevant species. Although such curvature-driven coarsening can occur rapidly in bulk 3-D materials, in thin films, the coarsening occurs slowly and typically halts when the average grain size $(2 \bar{r})$ reaches about the film thickness $(d)$, where all grain boundaries intersect the top surface and the bottom interface with the substrate (Figures $6 \mathrm{~B}-\mathrm{C}$ ). ${ }^{66}$ This coarsening "stagnation" is thought to be due to drag forces exerted by the surface and the interface on the moving grain boundaries, assuming isotropic grain-boundary energy. ${ }^{66}$ In particular, grain-boundary grooves at the surface are expected to exert significant drag force (Figure 6C inset). ${ }^{66}$ [Grain-boundary grooves in polycrystalline metals, ceramics, and inorganic semiconductors occur as a result of preferential evaporation or chemical attack of grain boundaries, which are more disordered compared to the grain interior.] Secondary coarsening (also referred to as exaggerated or abnormal grain growth) can occur in anisotropic thin films, where a few favorably oriented grains grow rapidly, resulting in large-grained, textured thin films (Figure 6D). ${ }^{66}$ The favorably oriented grains are the ones whose low-energy crystallographic planes constitute the thin-film surface and the interface with the substrate. The system tends to maximize the area of those surfaces and interfaces through the growth of the favorably oriented grains at the expense of the less favorably oriented grains. Thus, the coarsening rate of those favorably oriented grains (for radius $r_{\mathrm{S}} \gg \bar{r}$ ) is given by ${ }^{66}$

$$
\frac{\mathrm{d} r_{\mathrm{S}}}{\mathrm{d} t} \cong M\left[\frac{\left(\gamma_{\mathrm{CV}}^{*}+\gamma_{\mathrm{SC}}^{*}\right)-\left(\gamma_{\mathrm{CV}}+\gamma_{\mathrm{SC}}\right)+\gamma_{\mathrm{GB}}}{d}\right]
$$

where, $M$ is the grain-boundary mobility; $\gamma_{\mathrm{CV}}^{*}$ and $\gamma_{\mathrm{SC}}^{*}$ are the average surface and interface energies, respectively, of all the normal grains; $\gamma_{\mathrm{CV}}$ and $\gamma_{\mathrm{SC}}$ are the surface and interface energies, respectively, of the favorably oriented grains; and $\gamma_{\mathrm{GB}}$ is the grain-boundary energy. This implies that by minimizing the energy $\left(\gamma_{S C}\right)$ of the interface between the favorably oriented grains and the substrate through judicious choice of substrates for better adhesion, one could achieve rapid secondary graingrowth. In this context, the Dupré work of adhesion between the film and the substrate is given by ${ }^{67}$

$$
W_{\mathrm{SC}}=\gamma_{\mathrm{SV}}+\gamma_{\mathrm{CV}}-\gamma_{\mathrm{SC}}
$$

where $\gamma_{S V}$ is the surface energy of the substrate. (One may not have independent control over the energy terms except for $\gamma_{\mathrm{SC}}$ in eqs 6 and 7 for a given OTP.) This analysis suggests that grain sizes that are significantly larger than the film thickness $(d)$ can be obtained, and it is associated with strong crystallographic texture in the thin film, which can be a desirable attribute.

\section{This analysis suggests that grain sizes that are significantly larger than the film thickness can be obtained, and it is associated with strong crystallographic texture in the thin film, which can be a desirable attribute.}

The classical coarsening mechanism of Ostwald ripening typically requires a liquid phase to be present between the grains, where smaller grains with higher chemical potential by virtue of their curvature dissolve in the liquid. ${ }^{68}$ The liquid becomes locally supersaturated in "monomers", which deposit on larger grains with lower chemical potential resulting in the net coarsening of the grains. The Ostwald ripening process is limited either by the diffusion of the "monomers" through the liquid (diffusion-controlled) or by their attachment on the larger grains (interface-reaction controlled). The Ostwald ripening kinetics are also described by eq 5 , where the exponent $n=2$ for interface-reaction-controlled and $n=3$ for diffusion-controlled process. $^{68}$ Oswald ripening can occur via evaporationcondensation (vapor phase) as well, which is also driven by curvature differences and is described by eq $5 .^{69}$

Because the processing window (temperature, time) for both "one-step" and "two-step" methods is inherently limited due to the poor thermal stability of OTPs, the grain size of the as-deposited OTP thin films is typically small (few hundred nanometers). Thus, postdeposition grain growth/coarsening in dense OTP thin films has become important. However, there are only a few examples of grain growth/coarsening studies in OTP thin films in the literature. ${ }^{65,70,71}$ Xiao et al. ${ }^{70}$ report coarsening in $\mathrm{MAPbI}_{3}$ perovskite thin films (deposited using the "two step" interdiffusion method) during thermal annealing $\left(100{ }^{\circ} \mathrm{C}\right)$, where grains in a $\sim 300 \mathrm{~nm}$ thick film coarsen from $\sim 125 \mathrm{~nm}$ (as-formed) to $\sim 225 \mathrm{~nm}$ in $20 \mathrm{~min}$, but coarsening appears to "stagnate" at $60 \mathrm{~min}$. However, in the presence of a vapor (DMF), they observe significant grain growth; for the same $\sim 300 \mathrm{~nm}$ thin film, the grains were found to coarsen to $425 \mathrm{~nm}$ in $60 \mathrm{~min}\left(100^{\circ} \mathrm{C}\right)$. The coarsening behavior appears 


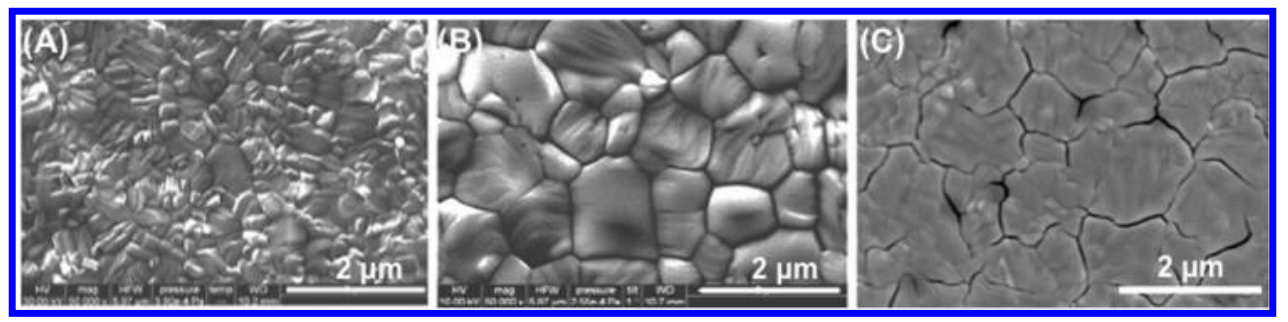

Figure 7. Top-view SEM micrographs of $\mathrm{MAPbI}_{3}$ perovskite thin films. (A) Thermally annealed without DMF vapor and (B) with DMF vapor. ${ }^{70}$ (C) Deposited using the antisolvent-solvent extraction method and annealed. ${ }^{71}$ Reprinted with permission of Wiley (copyright 2014, 2015).

to follow eq 5 with $n \sim 2$, suggesting interface-reactioncontrolled Ostwald ripening. This is not unexpected considering the facile diffusion of "monomers" and short diffusion lengths in this situation. Figure $7 \mathrm{~A}$ and $\mathrm{B}$ show the dramatic effect of the introduction of DMF vapor during heat-treatment on coarsening in a $1 \mu \mathrm{m}$ thick $\mathrm{MAPbI}_{3}$ perovskite film. ${ }^{70}$ These results also suggest that the presence of the solvent in the initial stages of the "one-step" process may promote coarsening by Ostwald ripening in competition with nucleation, which is highly undesirable. Thus, suppression of Ostwald ripening at that stage, by using lower temperatures, for example, is likely to promote high nuclei density needed for better film coverage in "one-step" processing. Another example of grain growth/ coarsening is from Yang et al., ${ }^{71}$ who heat-treated $\mathrm{MAPbI}_{3}$ perovskite thin films of $300 \mathrm{~nm}$ thickness (deposited using antisolvent-solvent extraction "one-step" method at room temperature with excess MAI) at $150{ }^{\circ} \mathrm{C}$ to result in coarsening from a few hundred nanometer in as-formed film to a few microns (with texture) in $15 \mathrm{~min}$ (Figure 7C).

OTP Microstructures: Grain Boundaries and Characterization. The most important microstructural quantity in polycrystalline OTP thin films-grain size-reported in the literature is almost exclusively determined based on the assumption that the as-formed grain-boundary grooves observed in the SEM on the top surface represent the intersection of each and every grain boundary with that surface. This assumption may not be valid because the way in which the grooves form during processing depends on how the grains grow and coalesce; these grooves are not produced deliberately by thermal- or chemical-etching as in the case of polycrystalline metals, ceramics, and inorganic semiconductors. In other words, there may be grain boundaries in the as-formed OTP thin films that may not form grooves during processing. Also, grain surfaces in as-deposited OTP thin films can have wrinkles, which can be mistaken for grainboundary grooves. For example, in the "hot-casting" method, where the OTP precursor is spin-coated or spread at high temperature, produces what appear to be "grains" that are several tens of microns to few millimeters wide. ${ }^{72}$ Recently, Zheng et al. ${ }^{49}$ and Deng et al. ${ }^{73}$ have used their own versions of the "hot-casting" method to deposit $\mathrm{MAPbI}_{3}$ thin films using different precursors and have concluded that the large "domains" (or aggregates) they observe are comprised of much smaller single-crystal grains and that there is strong delineation (grooving) of the boundaries between these "domains" compared to the boundaries between the grains within these "domains." This could be attributed to the unique ways in which these "domains" and the grains form and grow during the "hot-casting" process. ${ }^{74}$

For observing cross sections of OTP thin films in the SEM, fracturing is typically used for preparing such samples in the literature. Here, the fracturing process itself biases the creation of the observation surface. For example, in the "hot-cast" OTP thin films, ${ }^{73}$ fracture may occur preferentially at the weaker "domain" boundaries rather that the relatively stronger true grain boundaries, once again, resulting in the possible overestimation of the grain size.

To avoid such artifacts, it is imperative that more attention be paid to delineating the grain boundaries in OTP thin films accurately. The classical approach of polishing the top surfaces and the cross sections, followed by chemical or thermal etching, which is typically used in inorganic "hard" materials (metals, ceramics, semiconductors), may be impractical given the softness of OTPs and the thinness of the films. In this context, the SEM electron backscatter diffraction (EBSD) technique, which is routinely used to characterize the microstructures of polycrystalline metals and ceramics, ${ }^{75}$ could be used not only to confirm that the individual grains are single-crystalline but also to provide information about the crystallographic orientation of each grain (texture) and strain. However, high electron-beam voltages and long exposures are typically needed to obtain reliable EBSD data. Unfortunately, OTPs degrade under those conditions in the SEM precluding the application of EBSD in its current form. In fact, even moderate electron-beam exposure damages OTPs, in particular causing grain-boundary fracture during SEM observation (see e.g. Figures 3B (inset) and C, 5C (inset), and $7 \mathrm{C}$ ). Thus, there is an opportunity here to modify the EBSD method to suit OTPs. Another approach is to use focused ion beam (FIB) to "nanomachine" cross sections using a Ga-ion beam. This method too can damage OTPs, but it can be minimized, as discussed later in the context of preparing transmission electron microscopy (TEM) specimens using the FIB. Yet another promising nondestructive method is highresolution Kelvin-probe force microscopy (KFPM), which can map the surface potential at a $10 \mathrm{~nm}$ resolution over large areas. ${ }^{76}$ Grain boundaries invariably have higher potential relative to the grain interior, which can be easily detected by KFPM and mapped. ${ }^{77,78}$ Yang et al. ${ }^{71}$ recently reported the use of the high-resolution KPFM method, and the results are shown in Figure $8 \mathrm{~A}-\mathrm{B}$, where grain boundaries are clearly delineated. Also, what appear to be grain boundaries in some areas in the atomic force microscope (AFM) are wrinkles/steps rather than grain boundaries (see, e.g., circles in Figure $8 \mathrm{~A}-\mathrm{B}){ }^{71}$

TEM characterization has proved to be an effective way to understand OTP thin film microstructures in great detail. $^{20,21,60,71,79-83}$ Figure 9 show some examples of crosssectional TEM images of OTP thin films, where the TEM specimens are prepared using the FIB. ${ }^{60,71}$ Figure 9A is a crosssectional TEM image of the coarse-grained $\mathrm{MAPbI}_{3}$ thin film (in a planar PSC) corresponding to the one shown in Figure $7 \mathrm{C}^{71}$ In this TEM image, the vertical grain boundaries are delineated via light contrast, confirming the size of some grains to be $\sim 0.5 \mu \mathrm{m}$ (width), and that the grains span the entire thickness 


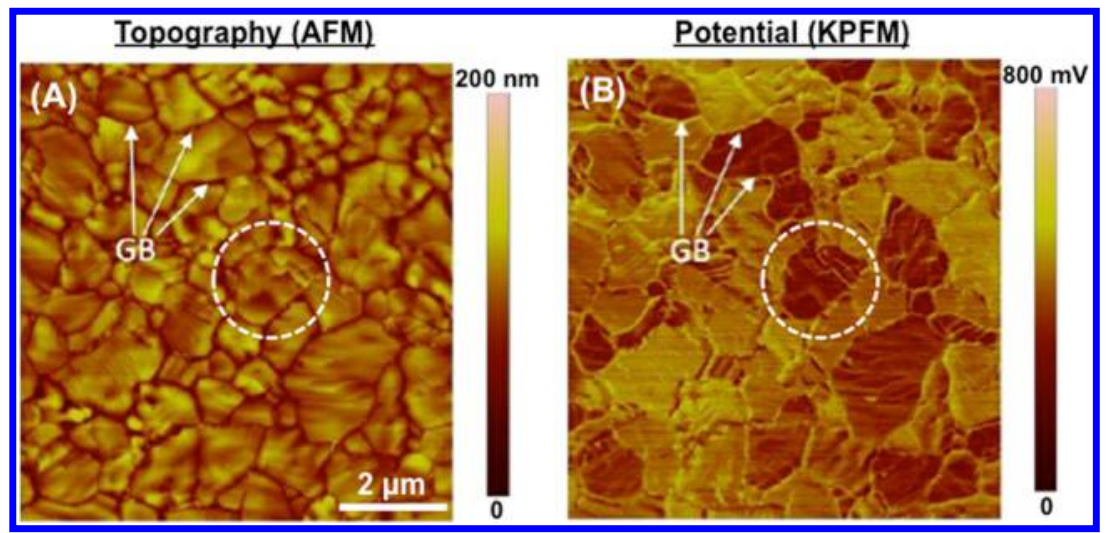

Figure 8. $\mathrm{MAPbI}_{3}$ perovskite thin film from Figure $7 \mathrm{C}$ imaged using (same area) (A) AFM and (B) KPFM. ${ }^{71}$ Reprinted with permission of Wiley (copyright 2015).

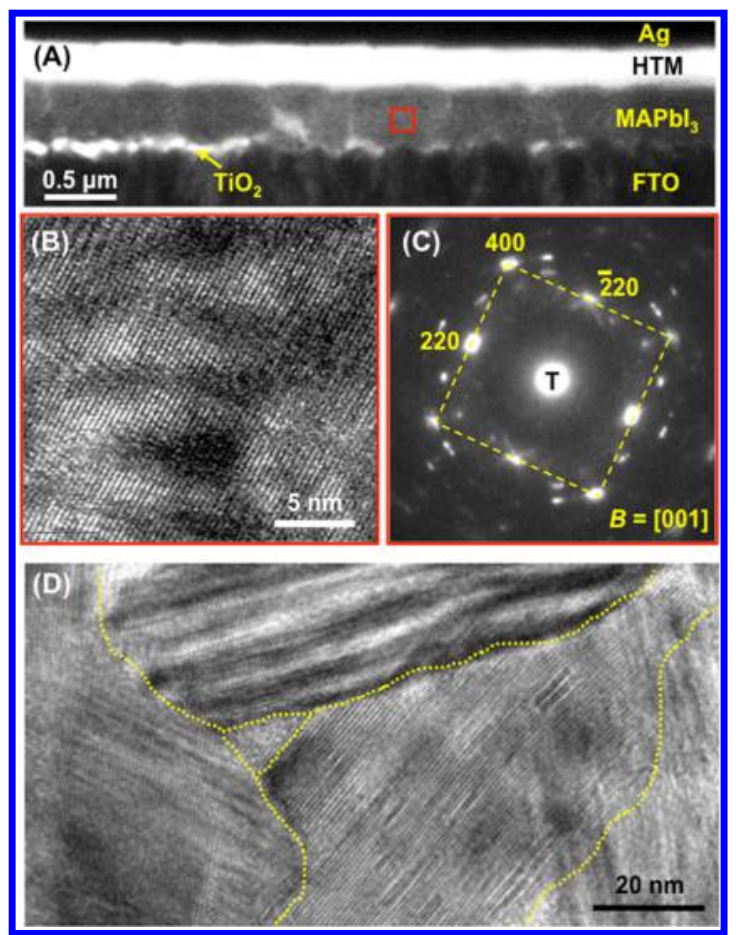

Figure 9. (A) Cross-sectional TEM image of planar PSC made with $\mathrm{MAPbI}_{3}$ thin film corresponding to Figure 7C, (B) high resolution TEM image of a $\mathrm{MAPbI}_{3}$ grain, and (C) indexed SAEDP from the marked area $(B$ is zone axis and $\mathrm{T}$ is transmitted beam $) .^{71}(\mathrm{D})$ Cross-sectional TEM image of $\mathrm{MAPbI}_{3}$ thin film deposited using the sequential spincoating and annealing "two-step" method, with the grain boundaries marked by yellow dashed curves. ${ }^{60}$ Reprinted with permission of Wiley (copyright 2015) and Royal Society of Chemistry (copyright 2015).

of the $\sim 300 \mathrm{~nm}$ thick film. Also note the "grooves" associated with the grain boundaries. It should be borne in mind that the TEM samples only a small volume of the film, and it cannot be used to determine average grain sizes. Figure $9 \mathrm{~B}$ is a high-resolution TEM image showing lattice fringes, and Figure $9 \mathrm{C}$ is the corresponding indexed selected area diffraction pattern (SAEDPs) confirming that the grains are $\beta-\mathrm{MAPbI}_{3}$ (space group $I 4 / \mathrm{mcm}$ ) perovskite single crystals, as evinced by the "spot" pattern rather than a polycrystalline "ring" pattern. ${ }^{71}$ $\mathrm{X}$-ray diffraction (XRD) studies confirm strong crystallographic texture in those films implying that most of the grains have similar orientation. Similar TEM characterization results have been obtained by Xiao et al. ${ }^{20}$ in $\mathrm{MAPbI}_{3}$ films deposited using the "fast deposition crystallization" "one-step" method. Figure 9D is a TEM image of a fine-grained $\mathrm{MAPbI}_{3}$ thin films (FIBed cross sections) deposited using a modified "two-step" method, ${ }^{60}$ where the grain boundaries are marked by dashed curves. The striking difference between these TEM micrographs, and those from conventional inorganic "hard" semiconductors (e.g., Si, CeTe, CIGS), is the proliferation of planar defects within the OTP grains and the occurrence of amorphous regions. It appears that the difference in the degree of disorder between the grain interiors and grain boundaries is less pronounced in OTPs compared to polycrystalline inorganic semiconductors. Perhaps this is to be expected in "soft" organic-inorganic hybrid materials like OTPs (elastic modulus 10-20 GPa, hardness $0.25-0.46 \mathrm{GPa}^{84}$ ). The defects within the grains and the grain boundaries have not been studied in any detail, primarily because of the electron-beam damage of OTPs during TEM studies requiring prolonged exposures. ${ }^{83}$ The FIBing process can also introduce damage, but ultralow beam voltages and currents are used to minimize that damage in preparing the TEM specimens in Figure 9. ${ }^{83}$ Also, related TEM studies of $\mathrm{MAPbI}_{3}$ perovskite thin films deposited directly onto TEM grids (without FIBing) show the presence of similar defects, suggesting that these defects are unlikely to be produced during the low-dose FIBing process. ${ }^{83}$

Thus, the challenges with the characterization of defects and microstructures of OTPs can be primarily attributed to the "soft" nature of the hybrid organic-inorganic OTPs. These challenges must be addressed in order to know the defects/ microstructure accurately, otherwise effort to control/tailor them through rational processing, and to establish microstructureproperties relations, may be misguided.

Nucleation/Growth of OTPs within Mesoporous Oxide Scaffolds. Mesoscopic PSCs, where the OTP forms within mesopores ( 5 to $20 \mathrm{~nm}$ ) of oxide scaffolds, are popular due to some advantages they offer over planar PSCs, such as reduced hysteresis in the current-density $(J)$-voltage $(V)$ response due to balanced extraction of electrons/holes, ${ }^{85}$ and better adhesion due to mechanical interlocking. In this case, much of the previous nucleation/growth discussion focused on the simpler case of flat OTP thin films for planar PSCs will need to be modified to consider the 3-D constraint placed by the scaffold. Although this problem is significantly more complex, constrained-crystallization theories developed in other fields ${ }^{86-89}$ could be adopted and built upon, at least in the simpler case of "one-step" processing of mesoscopic OTPs thin films. In the case of "two-step" processing of OTPs within mesoporous 
oxide scaffolds, the situation is much more complicated, and there are no relevant theories/analyses available to build upon. PSCs with some of the highest PCEs reported so far contain a mesoscopic layer, ${ }^{13}$ but without the deep understanding of crystallization of mesoscopic OTPs, further development of these PSCs will remain largely empirical. In the case of $\mathrm{FAPbI}_{3}$, which is polymorphic at room temperature, the mesoporous oxide scaffold affects its solution-crystallization not only in terms of the crystal morphology but also the phase. ${ }^{90}$ Detailed studies to address these shortcomings face formidable challenges, most of which are related to the small length (nanometers) and fast time (seconds) scales at which the relevant phenomenon occur, and the difficulty in the in situ and ex situ characterization at those scales.

Outlook. The progress made so far in the processing of OTP thin-film with desired morphologies and microstructures is truly remarkable, and it has been key to the rapid progress of the PSCs field itself and the excitement it has generated. However, most of the processing concepts in the OTPs literature are explained based on empirical correlations, causation arguments, and molecular/structural intuitions. Thus, there is a conspicuous gap in the materials-science understanding of how these chemical considerations actually translate into the formation of solid-state, polycrystalline OTP thin films over large areas. Although OTPs present formidable challenges, ${ }^{91}$ they offer unprecedented opportunities for not only advancing the materials science of OTPs for PSCs but also herald entirely new concepts in materials science. OTPs are a fascinating class of materials, falling into the hitherto uncharted territory between conventional "soft" materials (polymers) and "hard" crystalline materials (metals, ceramics, semiconductors). OTPs are "soft" materials with low formation energy, making them amenable to low-temperature solution processing, yet they are highly crystalline with microstructures remarkably similar to those of "hard" materials. The hybrid organic-inorganic nature of OTPs allows them to access the vast, rich field of organic/inorganic chemistry for their synthesis, yet materials-science principles of nucleation/growth, coarsening, grain-boundary topology/ dynamics, strain, and so forth can be applied for understanding their microstructural evolution. However, the "softness" and air-sensitivity of OTPs precludes the extensive use of some of the key characterization techniques (e.g., electron microscopy) essential for understanding OTPs' microstructural evolution and defects, yet OTPs are amenable to a vast array of spectroscopic methods.

$$
\begin{aligned}
& \text { The key advancements in the } \\
& \text { materials science of OTPs that are } \\
& \text { likely to have a long-lasting } \\
& \text { impact include (i) comprehensive } \\
& \text { elucidation of classical and } \\
& \text { non-classical nucleation/growth, } \\
& \text { coarsening, and microstructural } \\
& \text { evolution; (ii) deep understanding } \\
& \text { of defects and microstructures; } \\
& \text { and (iii) deterministic control over } \\
& \text { the processing of tailored OTP } \\
& \text { thin films. }
\end{aligned}
$$

Thus, the key advancements in the materials science of OTPs that are likely to have a long-lasting impact include (i) comprehensive elucidation of classical and nonclassical nucleation/growth, coarsening, and microstructural evolution; (ii) deep understanding of defects and microstructures; and (iii) deterministic control over the processing of tailored OTP thin films. These advancements will necessitate a concerted effort in in situ and ex situ characterization, guided by classical and nonclassical concepts in nucleation/growth, coarsening and microstructural evolution, and the relevant chemistry. This will require innovative modification of existing characterization techniques, or the development of altogether new characterization techniques with unprecedented spatial and temporal resolutions. These techniques will invariably entail new ways of exploiting the inherently different behavior/properties of the grain interior and the grain boundary while using low energy/ dose, benign probes to minimize, or eliminate, damage to OTPs. This could also have an impact on the characterization of other types of "soft" materials beyond OTPs. Furthermore, the expanding field of OTP single-crystals ${ }^{17}$ could benefit from the understanding of nucleation/growth, coarsening, and microstructural evolution in OTP thin films. Finally, there are unprecedented opportunities for bringing established and new computational materials science tools (e.g., ab initio molecular dynamics simulation, phase-field modeling, finite-element analysis, etc. $^{92}$ ) to bear in guiding the experimental effort. If the history of the development of several successful materialsintensive technologies, such as PVs, computer chips, lasers, solid-state lighting, gas-sensors, and so forth, is any guide, some of the enabling breakthroughs in PSCs technology are likely to come from these advancements in the materials-science understanding of OTPs.

\section{AUTHOR INFORMATION}

\section{Corresponding Authors}

*E-mail: yuanyuan zhou@brown.edu (Y.Z.).

*E-mail: nitin_padture@brown.edu (N.P.P.).

\section{Notes}

The authors declare no competing financial interest.

\section{Biographies}

Yuanyuan "Alvin" Zhou is a Ph.D. candidate in the School of Engineering at Brown University with a focus on materials science. His current research focuses on understanding crystallization mechanisms and fundamental properties of organolead trihalide perovskite and on developing scalable protocols for high-efficiency perovskite solar cells.

Onkar S. Game is a postdoctoral research associate in the School of Engineering at Brown University. His current research interests are in the optoelectronic characterization of organometal halide perovskite solar cells.

Shuping Pang is an associate professor at the Qingdao Institute of Bioenergy and Bioprocess Technology, Chinese Academy of Sciences. $\mathrm{He}$ obtained his Ph.D. from Max Planck Institute for Polymer Research in September 2011. His current research focus is on semiconductor materials (organometal halide perovskite, graphene, etc.) for energy storage and conversion.

Nitin P. Padture is a professor of materials science in the School of Engineering at Brown University and director of Brown's Institute for Molecular and Nanoscale Innovation. His current research interests are in advanced structural ceramics, including high-temperature coatings and damage-tolerant nanocomposites, and functional nanomaterials and devices, including graphene nanoelectronics and perovskite solar cells. 


\section{ACKNOWLEDGMENTS}

The funding from the National Science Foundation (Award Nos. DMR-1305913 and OIA-1538893) is gratefully acknowledged. S.P. acknowledges the research funding from the Chinese National Natural Science Foundation (Grant No. 51202266). We thank Dr. K. Zhu (NREL) and Prof. J. Huang (University of Nebraska-Lincoln) for fruitful discussions.

\section{REFERENCES}

(1) Weber, D. $\mathrm{CH}_{3} \mathrm{NH}_{3} \mathrm{SnBr}_{x} \mathrm{I}_{(3-x)}(x=0-3)-\mathrm{Sn}(\mathrm{II})$-System with Cubic Perovskite Sructure. Z. Naturforsch. 1978, 33b, 862-865.

(2) Weber, D. $\mathrm{CH}_{3} \mathrm{NH}_{3} \mathrm{PbX}_{3}, \mathrm{~A} \mathrm{~Pb}(\mathrm{II})$-System with Cubic Perovskite Structure. Z. Naturforsch., B: J. Chem. Sci. 1978, 33b, $1443-1445$.

(3) Mitzi, D. B. In Prog. Inorg. Chem.i Karlin, K. D., Ed.; John Wiley \& Sons: New York, 1999; Vol. 48, p 1-122.

(4) Kojima, A.; Teshima, K.; Shirai, Y.; Miyasaka, T. Organometal Halid Perovskites as Visible-Light Sensitizers for Photovoltaic Cells. I. Am. Chem. Soc. 2009, 131, 6050-6051.

(5) Im, J.-H.; Lee, C.-R.; Lee, J.-W.; Park, S.-W.; Park, N.-G. 6.5\% Efficient Perovskite Quantum-Dot-Sensitized Solar Cells. Nanoscale 2011, 3, 4088-4093.

(6) Kim, H.-S.; Lee, C.-R.; Im, J.-H.; Lee, K.-B.; Moehl, T.; Marchioro, A.; Moon, S.-J.; Humphry-Baker, R.; Yum, J.-H.; Moser, J. E.; et al. Lead Iodide Perovskite Sensitized All-Solid-State Submicron Thin Film Mesoscopic Solar Cell with Efficiency Exceeding 9\%. Sci. Rep. 2012, 2, 591.

(7) Lee, M. M.; Teuscher, J.; Miyasaka, T.; Murakami, T. N.; Snaith, H. J. Effcient Hybrid Solar Cells Based on Meso-Superstructured Organometal Halide Perovskites. Science 2012, 338, 643-647.

(8) Liu, M.; Johnston, M. B.; Snaith, H. J. Efficient Planar Heterojunction Perovskite Solar Cells by Vapor Deposition. Nature 2013, 501, 395-398.

(9) Snaith, H. J. Perovskites: The Emergence of a New Era for LowCost, High-Efficiency Solar Cells. I. Phvs. Chem. Lett. 2013, 4, 36233630.

(10) Graetzel, M. The Light and Shade of Perovskite Solar Cells. Nat. Mater. 2014, 13, 838-842.

(11) Green, M. A.; Ho-Baillie, A.; Snaith, H. J. The Emergance of Perovskite Solar Cells. Nat. Photonics 2014, 8, 506-513.

(12) Jung, H. S.; Park, N.-G. Perovskite Solar Cells: From Materials to Devices. Small 2015, 11, 10-25.

(13) Yang, W. S.; Noh, J. H.; Jeon, N. J.; Kim, Y. C.; Ryu, S.; Deo, J.; Seok, S. I.; Seo, J. High-Performance Photovoltaic Perovskite Layers Fabricated through Intramolecular Exchange. Science 2015, 348, 1234-1237.

(14) NREL. www.nrel.gov/ncpv/images/efficiency_chart.jpg (accessed October, 2015).

(15) Zhao, Y.; Zhu, K. Solution-Chemistry Engineering toward HighEfficiency Perovskite Solar Cells. I. Phvs. Chem. Lett. 2014, 5, 41754186.

(16) Stranks, S. D.; Nayak, P. K.; Zhang, W.; Stergiopoulos, T.; Snaith, H. J. Formation of Thin Films of Organic-Inorganic Perovskites for High-Efficiency Solar Cells. Angew. Chem. Int. Ed. 2015, 54, 3240-3248.

(17) Huang, J.; Shao, Y.; Dong, Q. Organometal Trihalide Perovskite Single Crystal: A New Next Wave of Materials for 25\% Efficiency Photovoltaics and Applications Beyond? I. Phvs. Chem. Lett. 2015, 6, 3218-3227.

(18) Im, J.-H.; Kim, H.-S.; Park, N.-G. Morphology-Photovoltaic Property Correlation in Perovskite Solar Cells: One-Step Versus TwoStep Deposition of $\mathrm{CH}_{3} \mathrm{NH}_{3} \mathrm{PbI}_{3}$. APL Mater. 2014, 2, 081510.

(19) Jeon, N. J.; Noh, J. H.; Kim, Y. C.; Yang, W. S.; Ryu, S.; Seok, S. I. Solvent Engineering for High-Performance Inorganic-Organic Hybrid Perovskite Solar Cells. Nat. Mater. 2014, 13, 897-903.

(20) Xiao, M.; Huang, F.; Huang, W.; Dkhissi, Y.; Zhu, Y.; Etheridge, J.; Gray-Weale, A.; Bach, U.; Cheng, Y.-B.; Spiccia, L. A Fast Deposition-Crystallization Procedure for Highly Efficient Lead Iodiade
Perovskite Thin-Film Solar Cells. Angew. Chem. Int. Ed. 2014, 53, 9898-9903.

(21) Zhou, Y.; Yang, M.; Wu, W.; Vasiliev, A. L.; Zhu, K.; Padture, N. P. Room-Temperature Crystallization of Hybrid-Perovskite Thin Films Via Solvent-Solvent Extraction for High-Performance Solar Cells. I. Mater. Chem. A 2015, 3, 8178-8184.

(22) Shi, D.; Adinolfi, V.; Comin, R.; Yuan, M.; Alarousu, E.; Buin, A.; Chen, Y.; Hoogland, A.; Rothenberger, A.; Katsiev, K.; et al. Low Trap Density and Long Carrier Diffusion in Organolead Trihalide Perovskite Single Crystals. Science 2015, 347, 519-522.

(23) Zhou, Z.; Wang, Z.; Zhou, Y.; Pang, S.; Wang, D.; Xu, H.; Liu, Z.; Padture, N. P.; Cui, G. Methylamine-Gas-Induced Defect-Healing Behavior of $\mathrm{CH}_{3} \mathrm{NH}_{3} \mathrm{PbI}_{3}$ Thin Films for Perovskite Solar Cells. Angew. Chem.. Int. Ed. 2015, 54, 9705-9709.

(24) Yoreo, J. J. D.; Gilbert, P. U. P. A.; Sommerdijk, N. A. J. M.; Penn, R. L.; Whitelam, S.; Joester, D.; Zhang, H.; Rimer, J. D.; Navrotsky, A.; Banefield, J. F.; et al. Crystallization by Particle Attachement in Synthetic, Biogenic, and Geologic Environments. Science 2015, 349, aaa6760.

(25) Nielsen, A. E. Kinetics of Precipitation; Pergamon: Oxford, 1964.

(26) Brinker, C. J.; Scherer, G. W. Sol-Gel Science; Academic Press: New York, 1990.

(27) Adamson, A. W.; Gast, A. P. Physical Chemistry of Surfaces; Wiley: New York, 1997.

(28) Ring, T. A. Fundamentals of Ceramic Powder Processing and Synthesis; Academic Publishers: New York, 1996.

(29) Wakamiya, A.; Endo, M.; Sasamori, T.; Tokitoh, N.; Ogomi, Y.; Hayase, S.; Murata, Y. Reproducible Fabrication of Efficient Perovskite-Based Solar Cells: X-Ray Crystallographic Studies on the Formation of $\mathrm{CH}_{3} \mathrm{NH}_{3} \mathrm{PbI}_{3}$ Layers. Chem. Lett. 2014, 43, 711-713.

(30) Stamplecoskie, K. G.; Manser, J. S.; Kamat, P. V. Dual Nature of the Excited State in Organic-Inorganic Lead Halide Perovskites. Energy Environ. Sci. 2014, 8, 208-215.

(31) Davidovich, R. L.; Stavila, V.; Marinin, D. V.; Voit, E. I.; Whitmire, K. H. Stereochemistry of Lead(Ii) Complexes with Oxygen Donor Ligands. Coord. Chem. Rev. 2009, 253, 1316-1352.

(32) Yan, K.; Long, M.; Zhang, T.; Wei, Z.; Chen, H.; Yang, S.; Xu, J. Hybrid Halide Perovskite Solar Cel Precursors: Colloidal Chemistry and Coordination Engineering Behind Device Processing for High Efficiency. I. Am. Chem. Soc. 2015, 137, 4460-4468.

(33) Wu, Y.; Islam, A.; Yang, X.; Qin, C.; Liu, J.; Zhang, K.; Peng, W.; Han, L. Retarding the Crystallization of $\mathrm{PbI}_{2}$ for Highly Reprodicible Planar-Structured Perovskite Solar Cells Via Sequential Deposition. Energy Environ. Sci. 2014, 7, 2934-2938.

(34) Rong, Y.; Tang, Z.; Zhao, Y.; Zhong, X.; Venkatesan, S.; Graham, H.; Patton, M.; Jing, Y.; Guloy, A. M.; Yao, Y. Solvent Engineering Towards Controlled Grain Growth in Perovskite Planar Heterojunction Solar Cells. Nanoscale 2015, 7, 10595-10599.

(35) Wang, W. Q.; Shao, Y.; Dong, Q.; Xiao, Z.; Yuan, Y.; Huang, J. Large Fill-Factor Bilayer Iodine Perovskite Solar Cells Fabricated by a Low-Temperature Solution-Process. Energy Environ. Sci. 2014, 7, 2359-2365.

(36) Kang, R.; Kim, J.-E.; Yeo, J.-S.; Lee, S.; Jeon, Y.-J.; Kim, D.-Y. Optimized Organolead Halide Perovskite Planar Hybrid Solar Cells via Control of Solvent Evapportaion Rate. I. Phys. Chem. C 2014, 118, 26513-26520.

(37) Kim, H.-B.; Choi, H.; Jeong, J.; Kim, S.; Walker, B.; Song, S.; Kim, J. Y. Mixed Solvents for the Optimization of Morphology in Solution-Processed, Inverted-Type Perovskite/Fullerene Hybrid Solar Cells. Nanoscale 2014, 6, 6679-6683.

(38) Wang, J.; Wang, N.; Jin, Y.; Si, J.; Tan, Z.-K.; Du, H.; Cheng, L.; Dai, X.; Bai, S.; He, H.; et al. Interfacial Control toward Efficient and Low-Voltage Perovskite Light-Emitting Diodes. Adv. Mater. 2015, 27, 2311-2316.

(39) Moore, D. T.; Tan, K. W.; Sai, H.; Barteau, K. P.; Wiesner, U.; Estroff, L. A. Direct Crystallization Route to Methylammonium Lead Iodide Perovskite from an Ionic Liquid. Chem. Mater. 2015, 27, 31973199. 
(40) Manser, J. S.; Reid, B.; Kamat, P. V. Evolution of OrganicInorganic Lead Halide Perovskite from Solid-State Iodoplumbate Complexes. I. Phvs. Chem. C 2015, 119, 17065-17073.

(41) Zhao, Y.; Zhu, K. $\mathrm{CH}_{3} \mathrm{NH}_{3} \mathrm{Cl}$-Assisted One-Step Solution Growth of $\mathrm{CH}_{3} \mathrm{NH}_{3} \mathrm{PbI}_{3}$ : Structure, Charge-Carrier Dynamics, and Photovoltaic Properties of Perovskite Solar Cells. L. Phvs. Chem. C 2014, 118, 9412-9418.

(42) Zuo, C.; Ding, L. An 80.11\% FF Record Achieved for Perovskite Solar Cells by Using the $\mathrm{NH}_{4} \mathrm{Cl}$ Additive. Nanoscale 2014, 6, 99359938.

(43) Moore, D. T.; Sai, H.; Tan, K. T.; Smilgies, D.-M.; Zhang, W.; Snaith, H. J.; Wiesner, U.; Estroff, L. A. Crystallization Kinetics of Organic-Inorganic Trihalide Perovskites and the Role of the Lead Anion in Crystal Growth. I. Am. Chem. Soc. 2015, 137, 2350-2358.

(44) Zhang, W.; Saliba, M.; Moore, D. T.; Pathak, S. K.; Horantner, M. T.; Stergiopoulos, T.; Stranks, S. D.; Eperon, G. E.; AlexanderWebber, J. A.; Abate, A.; et al. Ulrasmooth Organic-Inorganic Perovskite Thin-Film Formation and Crystallization for Efficient Planar Heterojunction Solar Cells. Nat. Commun. 2015, 6, 6142.

(45) Lv, S.; Pang, S.; Zhou, Y.; Padture, N. P.; Hu, H.; Wang, L.; Zhou, X.; Zhu, H.; Zhang, L.; Huang, C.; et al. One-Step, SolutionProcessed Formamidinium Lead Trihalide $\left(\mathrm{FAPbI}_{(3-x)} \mathrm{Cl}_{x}\right)$ for Mesoscopic Perovskite-Polvmer Solar Cells. Phys. Chem. Chem. Phys. 2014, 16, 19206-19211.

(46) Eperon, G. E.; Stranks, S. D.; Menelaou, C.; Johnston, M. B.; Herz, L. M.; Snaith, H. J. Formamidinium Lead Trihalide: A Broadly Tunable Perovskite for Efficient Planar Heterojunction Solar Cells. Energy Environ. Sci. 2014, 7, 982-988.

(47) Wang, F.; Yu, H.; Xu, H.; Zhao, N. $\mathrm{HPbI}_{3}$ : A New Precusor Compound for Highly Efficient Solution-Processed Perovskite Solar Cells. Adv. Funct. Mater. 2015, 25, 1120-1126.

(48) Barata, P. A.; Serrano, M. L. Salting-out Precipitation of Potassium Dihydrogen Phosphate (KDP): I, Precipitation Mechanism. I. Crust. Growth 1996, 160, 361-369.

(49) Zheng, Y. C.; Yang, S.; Chen, X.; Chen, Y.; Hou, Y.; Yang, H. G. Thermal-Induced Volmer-Weber Growth Behvaior for Planar Heterojunction Perovskites Solar Cells. Chem. Mater. 2015, 27, $5116-5121$.

(50) Venables, J. A.; Spiller, G. D. T.; Hanbucken, M. Nucleation and Growth of Thin Films. Rep. Prog. Phvs. 1984, 47, 399-459.

(51) Hu, H.; Wang, D.; Zhou, Y.; Zhang, J.; Lv, S.; Pang, S.; Chen, X.; Liu, Z.; Padture, N. P.; Cui, G. Vapour-Based Processing of HoleConductor-Free $\mathrm{CH}_{3} \mathrm{NH}_{3} \mathrm{PbI}_{3}$ Perovskite/ $\mathrm{C}_{60}$ Fullerene Planar Solar Cells. RSC Adv. 2014, 4, 28964-28967.

(52) Zhou, Y.; Yang, M.; Kwun, J.; Game, O. S.; Zhao, Y.; Pang, S.; Padture, N. P.; Zhu, K. Nanoscale 2016, DOI: 10.1039/C5NR06189J.

(53) Lee, J.-W.; Park, N.-G. Two-Step Deposition Method for HighEfficiency Perovskite Solar Cells. MRS Bull. 2015, 40, 654-659.

(54) Burschka, J.; Pellet, N.; Moon, S.-J.; Humphry-Baker, R.; Gao, P.; Nazeeruddin, M. K.; Grätzel, M. Sequential Deposition as a Route to High-Performance Perovskite-Sensitized Solar Cells. Nature 2013, 499, 316-319.

(55) Xiao, Z.; Bi, C.; Shao, Y.; Dong, Q.; Yuan, Y.; Wang, C.; Gao, Y.; Huang, J. Efficient, High Yield Perovskite Photovoltaic Devices Grown by Interdiffusion of Solution-Processed Precursor Stacking Layers. Energy Environ. Sci. 2014, 7, 2619-2623.

(56) Chen, Q.; Zhou, H.; Hong, Z.; Luo, S.; Duan, H.-S.; Wang, H.H.; Liu, Y.; Li, G.; Yang, Y. Planar Heterojunction Perovskite Solar Cells Via Vapor-Assisted Solution Process. I. Am. Chem. Soc. 2014, 136, 622-625.

(57) Kingery, W. D.; Bowen, H. K.; Uhlmann, D. R. Introduction to Ceramics, 2nd ed.; Wiley Interscience: New York, 1976.

(58) Stoumpos, C. C.; Malliakas, C. D.; Kanatzidis, M. G. Semiconducting Tin and Lead Iodide Perovskites with Organic Cations: Phase Transformations, High Mobilities, and near-Infrared Photoluminescent Properties. Inorg. Chem. 2013, 52, 9019-9038.

(59) Schlipf, J.; Docampo, P.; Schaffer, C. J.; Korstgens, V.; Bießmann, L.; Hanusch, F.; Giesbrecht, N.; Bernstorff, S.; Bein, T.; Müller-Buschbaum, P. A Closer Look into Two-Step Perovskite
Conversion with X-Ray Scattering. I. Phvs. Chem. Lett. 2015, 6, 12651269.

(60) Zhou, Y.; Yang, M.; Vasiliev, A. L.; Garces, H. F.; Zhao, Y.; Wang, D.; Pang, S.; Zhu, K.; Padture, N. P. Growth Control of Compact $\mathrm{CH}_{3} \mathrm{NH}_{3} \mathrm{PbI}_{3}$ Thin Films via Enhanced Solid-State Precursor Reaction for Efficient Planar Perovskite Solar Cells. I. Mater. Chem. A 2015, 3, 9249-9256.

(61) Zhang, T.; Yang, M.; Zhao, Y.; Zhu, K. Controllable Sequential Deposition of Planar $\mathrm{CH}_{3} \mathrm{NH}_{3} \mathrm{PbI}_{3}$ Perovskite Films via Adjustable Volume Expansion. Nano Lett. 2015, 15, 3959-3963.

(62) Li, W.; Fan, J.; Li, J.; Mai, Y.; Wang, L. Controllable Grain Morphology of Perovskite Absorber Film by Molecular Self-Assembly toward Efficient Solar Cell Exceeding 17\%. I. Am. Chem. Soc. 2015, 137, 10399-10405.

(63) Luque, A.; Hegedus, S. Handbook of Photovoltaic Science and Engineering: Wiley: New York, 2011.

(64) Quilettes, D. W. d.; Vorpahl, S. M.; Stranks, S. D.; Nagaoka, H.; Eperon, G. E.; Ziffer, M. E.; Snaith, H. J.; Ginger, D. S. Impact of Microstructure on Local Carrier Lifetime in Perovskite Solar Cells. Science 2015, 348, 683-686.

(65) Cheng, B.; Wang, Q.; Shao, Y.; Yuan, Y.; Xiao, Z.; Huang, J. Non-Wetting Surface-Driven High-Aspect-Ratio Crystalline Grain Growth for Efficient Hybrid Perovskite Solar Cells. Nat. Commun. 2015, 6, 7747.

(66) Thompson, C. V. Grain Growth in Thin Films. Annu. Rev. Mater. Sci. 1990, 20, 245-268.

(67) Lawn, B. R. Fracture of Brittle Solids, 2nd ed.; Cambridge University Press: Cambridge, 1993.

(68) Vorhees, P. W. Ostwald Ripening of Two-Phase Mixtures. Annu. Rev. Mater. Sci. 1992, 22, 197-215.

(69) Readey, M. J.; Readey, D. W. Sintering of $\mathrm{ZrO}_{2}$ in $\mathrm{HCl}$ Atmopsheres. I. Am. Ceram. Soc. 1986, 69, 580-582.

(70) Xiao, Z. G.; Dong, Q. F.; Bi, C.; Shao, Y. C.; Yuan, Y. B.; Huang, J. S. Solvent Annealing of Perovskite-Induced Crystal Growth for Photovoltaic-Device Efficiency Enhancement. Adv. Mater. 2014, 26, 6503-6509.

(71) Yang, M.; Zhou, Y.; Zeng, Y.; Jiang, C.-S.; Zhu, K. SquareCentimeter Solution-Processed Planar $\mathrm{CH}_{3} \mathrm{NH}_{3} \mathrm{PbI}_{3}$ Perovskite Solar Cells with Efficiency Exceeding 15\%. Adv. Mater. 2015, 27, 6363.

(72) Nie, W.; Tsai, H.; Asadpour, R.; Blancon, J.-C.; Neukirch, A. J.; Gupta, G.; Crochet, J. J.; Chhowalla, M.; Tretiak, S.; Alam, M. A.; et al. High-Efficiency Solution-Processed Perovskite Solar Cells with Millimeter-Scale Grains. Science 2015, 347, 522-525.

(73) Deng, Y.; Peng, E.; Shao, Y.; Xiao, Z.; Dong, Q.; Huang, J. Scalable Fabrication of Efficient Organolead Trihalide Perovskite Solar Cells with Doctor-Bladed Active Layers. Energy Environ. Sci. 2015, 8, 1544-1550.

(74) Deng, Y.; Wang, Q.; Yuan, Y.; Huang, J. Vivid Colorful Hybrid Perovskite Solar Cells by Doctor-Blade Coating with Perovskite Photonic Nanostructures. Mater. Horiz. 2015, 2, 578.

(75) Wilkinson, A. J.; Britton, T. B. Strain, Planes, and EBSD in Materials Science. Mater. Todav 2012, 15, 366-376.

(76) Jiang, C.-S.; Contreras, M. A.; Mansfield, L. M.; Moutinho, H. R.; Egaas, B.; Ramanathan, K.; Al-Jassim, M. M. Nanometer-Scale Surface Potential and Resistance Mapping of Wide-Bandgap Cu(in,Ga)Se $\mathrm{Se}_{2}$ Thin Films. Appl. Phvs. Lett. 2015, 106, 043901.

(77) Yun, J. S.; Ho-Baillie, A.; Huang, S.; Woo, S. H.; Heo, Y.; Seidel, J.; Huang, F.; Cheng, Y.-B.; Green, M. A. Benefit of Grain Boundaries in Organic-Inorganic Halide Planar Perovskite Solar Cells. I. Phvs. Chem. Lett. 2015, 6, 875-880.

(78) Edri, E.; Kirmayer, S.; Henning, A.; Mukhopadhyay, S.; Gartsman, K.; Rosenwaks, Y.; Hodes, G.; Cahen, D. Why Lead Methylammonium Tri-iodide Perovskite-Based Solar Cells Require a Mesoporous Electron Transporting Scaffold (But not Necessarily a Hole Conductor)? Nano Lett. 2014, 14, 1000-1004.

(79) Nanova, D.; Kast, A. K.; Pfannmoller, M.; Müller, C.; Veith, L.; Wacker, I.; Agari, M.; Hermes, W.; Erk, P.; Kowalsky, W.; et al. Unraveling the Nanoscale Morphologies of Mesoporous Perovskite 
Solar Cells and Their Correlation to Device Performance. Nano Lett. 2014, 14, 2735-2740.

(80) Huang, F.; Dkhissi, Y.; Huang, W.; Xiao, M.; Benesperi, I.; Rubanov, S.; Zhu, Y.; Lin, X.; Jiang, L.; Zhou, Y.; et al. Gas-Assisted Preparation of Lead Iodide Perovskite Films Consisting of a Monolayer of Single Crystalline Grains for High Efficiency Planar Solar Cells. Nano Energy 2014, 10, 10-18.

(81) Zushi, M.; Suzuki, A.; Akiyama, T.; Oku, T. Fabrication and Characterization of $\mathrm{TiO}_{2} / \mathrm{CH}_{3} \mathrm{NH}_{3} \mathrm{PbI}_{3}$-Based Photovoltaic Devices. Chem. Lett. 2014, 43, 916-918.

(82) Ogomi, Y.; Kukihara, K.; Qing, S.; Toyoda, T.; Yoshino, K.; Pandey, S.; Momose, H.; Hayase, S. Control of Charge Dynamics through a Charge-Speration Interface for All-Solid Perovskite-Sensitied Solar Cells. ChemPhysChem 2014, 15, 1062-1069.

(83) Zhou, Y.; Vasiliev, A. L.; Wu, W.; Yang, M.; Pang, S.; Zhu, K.; Padture, N. P. Crystal Morphologies of Organolead Trihalide in Mesoscopic/Planar Perovskite Solar Cells. L. Phys. Chem. Lett. 2015, 6, 2292-2297.

(84) Sun, S.; Fang, Y.; Kieslich, G.; White, T. J.; Cheetham, A. K. Mechanical Properties of Organic-Inorganic Halide Perovskites, $\mathrm{CH}_{3} \mathrm{NH}_{3} \mathrm{PbX}_{3}(\mathrm{X}=\mathrm{I}, \mathrm{Br}$ and $\mathrm{Cl})$, by Nanoindentation. L. Mater. Chem. A 2015, 3, 18450.

(85) Snaith, H. J.; Abate, A.; Ball, J. M.; Eperon, G. F.; Leijtens, T.; Noel, N. K.; Stranks, S. D.; Wang, J. T.-W.; Wojciechowski, K.; Zhang, W. Anomalous Hysteresis in Perovskite Solar Cells. L. Phvs. Chem. Lett. 2014, 5, 1511-1515.

(86) Padture, N. P.; Chan, H. M. On the Constrained Crystallization of Synthetic Anorthite $\left(\mathrm{CaO} \cdot \mathrm{Al}_{2} \mathrm{O}_{3} \cdot 2 \mathrm{SiO}_{2}\right)$. L. Mater. Res. 1992, 7, $170-177$.

(87) Scherer, G. W. Crystallization in Pores. Cem. Concr. Res. 1999, 29, 1347-1358.

(88) Scherer, G. W. Stress from Crystallization of Salt. Cem. Concr. Res. 2004, 34, 1613-1624.

(89) Steiger, M. Crystal Growth in Porous Materials - II: Influence of Crystal Size on the Crystallization Pressure. I. Cryst. Growth 2005, 282, $470-481$.

(90) Wang, Z.; Zhou, Y.; Pang, S.; Xiao, Z.; Zhang, J.; Chai, W.; Xu, H.; Liu, Z.; Padture, N. P.; Cui, G. Chem. Mater. 2015, 27, 7149-7155.

(91) Berry, J.; Buonassisi, T.; Egger, D. A.; Hodes, G.; Kronik, L.; Loo, Y.-L.; Lubomirsky, I.; Marder, S. R.; Matsai, Y.; Miller, J. S.; et al. Hybrid Organic-Inorganic Perosvkites (HOIPs): Opportunities and Challenges. Adv. Mater. 2015, 27, 5102-5112.

(92) LeSar, R. Computational Materials Science: Fundamentals to Applications; Cambridge University Press: Cambridge, 2013. 